\title{
Instituições e Políticas Moldando o Desenvolvimento Industrial: uma nota introdutória'
}

\author{
Mario Cimoli \\ CEPAL, Nações Unidas, Santiago, Chile \\ Giovanni Dosi \\ Sant'Anna School of Advanced Studies, Pisa, Itália \\ Richard R. Nelson \\ Columbia University, Nova York \\ Joseph Stiglitz \\ Columbia University, Nova York
}

\section{RESUMO}

Neste trabalho, elaborado como introdução às contribuições da força-tarefa sobre Politicas Industriais e Desenvolvimento, Iniciativa para o Diálogo sobre Políticas (Columbia University, Nova York), discutimos o papel das instituições e políticas no processo de desenvolvimento. Iniciamos argumentando sobre o quanto a terminologia das "falhas de mercado" pode ser enganosa para avaliar a necessidade de políticas públicas por fazer essa avaliação com base num padrão de medida que é raramente observado em qualquer mercado. Muito mais próximos da evidência empírica, nós argumentamos que mesmo quando o mercado prevalece como forma de governança de interaçôes econômicas, estas se encontram entranhadas numa rica

1 Preparado para a Força-Tarefa sobre "Políticas Industriais e Desenvolvimento", no âmbito da Iniciativa para o Diálogo sobre Políticas (IPD - Initiative for Policy Dialogue), dirigida por Joseph Stiglitz na Columbia University, Nova York. Submetido à RBI para publicação exclusivamente em português. A versão original, em inglês, será publicada em livro a ser editado pela Oxford University Press.

N.E. A tradução deste artigo é da autoria do Professor José Emílio Maiorino, da Editora UNICAMP; a revisão técnica do texto é do editor associado, Professor Tamás Szmrecsányi (DPCT-IG/UNICAMP). O texto final foi revisto pelo Editor. 
malha de instituições não-mercado. Isto se aplica de modo geral e particularmente à produção e uso de informação e conhecimento tecnológico. Neste trabalho nos baseamos nesse entranhamento institucional fundamental de processos de aprendizado tecnológico, tanto em países desenvolvidos quanto em países que buscam alcançar a fronteira tecnológica (catching-up), e tentamos identificar alguns ingredientes robustos de políticas que têm historicamente acompanhado a co-evolução de capacitações tecnológicas, formas de organização das empresas, e mecanismos de incentivos. Todas as experiências bem-sucedidas de catching-up e, às vezes, superação dos líderes econômicos prevalecentes - a começar pelos Estados Unidos em relação à Grã-Bretanha - envolveram "construção institucional" e medidas de políticas que afetam a imitação tecnológica, a organização de indústrias, padrões de comércio internacional, e direitos de propriedade intelectual. Argumentamos que isto certamente se aplica hoje também, mesmo no contexto de uma economia mundial "globalizada".

PALAVRAS-ChaVE | Política Industrial; Desenvolvimento Industrial; Instituições Códigos JEL I F13; O14; O20; O38

\section{ABSTRACT}

In this work, meant as an introduction to the contributions of the task force on Industrial Policies and Development, Initiative for Policy Dialogue, Columbia University, New York, we discuss the role of institutions and policies in the process of development. We begin by arguing how misleading the "market failure" language can be in order to assess the necessity of public policies in that it evaluates it against a yardstick that is hardly met by any observed market set-up. Much nearer to the empirical evidence we argue that even when one encounters a prevailing market form of governance of economic interactions, the latter are embedded in a rich thread of non-market institutions. This applies in general and is particularly so with respect to the production and use of information and technological knowledge. In this work we build on the fundamental institutional embeddedness of such processes of 
technological learning in both developed and catching-up countries and we try to identify some quite robust policy ingredients which have historically accompanied the co-evolution between technological capabilities, forms of corporate organisations and incentive structures. All experiences of successful catching-up and sometimes overtaking the incumbent economic leaders - starting with the USA vis-à-vis Britain - have involved "institution building” and policy measures affecting technological imitation, the organisations of industries, trade patterns and intellectual property rights. This is likely to apply today, too, - we argue - also in the context of a "globalised" world economy.

KeYWords | Industrial Policy; Industrial Development; Institutions

JEL-CODES I F13; O14; O20; O38

\section{Introdução}

Há duas maneiras complementares de se introduzir a análise das instituições e políticas que dão forma ao desenvolvimento industrial.

Em primeiro lugar, pode-se partir da simples constatação empírica de que não é possível encontrar na história qualquer exemplo de um processo de desenvolvimento inserido em um ambiente que se assemelhe, ainda que vagamente, às histórias de interações econômicas desvinculadas de instituições, encontráveis em boa parte da teoria econômica contemporânea. Ao contrário, todas as experiências históricas de crescimento econômico sustentado - desde pelo menos a "Revolução Industrial" inglesa - têm encontrado as condições que as tornam possíveis dentro de um rico conjunto de instituições complementares, normas de comportamento compartilhadas e políticas públicas. $\mathrm{Na}$ verdade, a suprema importância das instituiçōes e das normas sociais parece 
constituir uma espécie de propriedade universal de todas as formas de organização coletiva de que temos conhecimento. Além disso, e num sentido mais restrito, as políticas públicas discricionárias têm sido importantes ingredientes das estratégias de desenvolvimento nacional, especialmente nos países em processo de emparelhamento (catching up), ao longo de toda a história do capitalismo moderno: cf. as contribuições de Mazzoleni e Nelson (2005), e Perez e Di Maio (2006) a este projeto, juntamente com as experiências históricas analisadas nos capítulos dedicados aos diferentes países.

Ao mesmo tempo, a partir de uma perspectiva simétrica, há razões teóricas extremamente sólidas em apoio à tese de que as instituições e as políticas sempre têm importância em todos os processos de aprendizado tecnológico e de coordenação e mudança econômicas.

Aqui, iremos focalizar este último aspecto, delineando alguns fundamentos teóricos para a criação de instituições e o estabelecimento de políticas.

\section{Um ponto de partida enganoso: as "falhas de mercado"}

Em termos convencionais, poderíamos partir de uma questão bastante geral sobre quando se requerem políticas públicas do ponto de vista da teoria; como sabemos, a resposta padrão seria "quando existirem falhas de mercado" de algum tipo. Contudo, embora seja muito comum, a terminologia das "falhas de mercado" tende a ser bastante enganosa na medida em que, para avaliar a necessidade e a eficácia de qualquer política, utiliza como padrão de medida as condições sob as quais são válidos os teoremas normativos (de "bem-estar") comuns. O problema suscitado por tal esquema não é o das "falhas de mercado" serem irrelevantes. Ao contrário: o problema está em que dificilmente uma situação empírica qualquer apresentará alguma semelhança significativa com tal "padrão de medida" - por exemplo, em termos de plenitude do mercado, de perfeição da concorrência, dos conhecimentos possuídos pelos agentes econômicos, da imutabilidade das tecnologias e preferências, da "racionalidade" da tomada de decisões, etc. (a lista é mesmo muito longa!). Num sentido mais profundo, quando julgado segundo esses padrões gerais, o mundo inteiro pode ser encarado como uma enorme falha de mercado!

Com efeito, isso é implicitamente reconhecido em todas as discussões sérias 
a respeito de políticas, nas quais o foco do debate quase nunca é o fato da situação em pauta ser realmente "ótima” mas, preferivelmente, de se os problemas com o arranjo institucional oficial são suficientemente severos para garantir medidas de políticas ativas. Em tudo isso, na maioria das vezes, a demanda por "testes de falhas" atua principalmente como um dispositivo para afastar o ônus da prova daqueles que acreditam no dogma segundo o qual, em geral, "mais mercado é sempre melhor do que menos...”.

Muito mais próximos das realidades empíricas dos mercados e das instituições não-mercantis que governam a produção, as trocas e a coordenação econômica nas economias modernas, discutiremos no que segue ambas as questões $(i)$ das fronteiras entre as formas mercantis e não-mercantis de organização econômica, e (ii) da inserção dos próprios mercados no interior de instituições não-mercantis complementares.

\section{Um papel quase universal das instituições: a determinação das fronteiras entre as interações mercantis e não-mercantis}

Que tipos de atividades sociais estão sujeitos (i) a produção descentralizada e (ii) a trocas mediadas por dinheiro, e que tipos não estão? Há um rol impressionante abrangendo desde o economicamente banal até o moralmente ultrajante. Trata-se de bens "estratégicos"? fármacos? monopólios "naturais"? serviços públicos? educação? creches? benefícios de aposentados? serviços de saúde? órgãos humanos? sangue? maridos e mulheres? votos políticos? filhos? decisões judiciais?

Em outro trabalho, um de nós (Nelson, 2005) discute exatamente a estrutura de governança de alguns bens e serviços cuja oferta tenha dependido com freqüência, em parte ou integralmente, de mecanismos não-mercantis.

É claro que a questão da determinação dos limites do mercado vale tanto para os países desenvolvidos quanto para os países em desenvolvimento, mas ela é particularmente crucial para as economias emergentes e as oriundas de sistemas centralmente planificados, nos quais as fronteiras entre as instituições mercantis e não-mercantis ainda precisam ser claramente definidas. Longe do furor dos fundamentalistas do mercado, nosso ponto de vista básico sobre essa questão é o de que as instituições não-mercantis (incluindo desde agências 
públicas até associações profissionais, e desde sindicatos até estruturas comunitárias) situam-se no cerne da própria constituição de todo o tecido socioeconômico. O papel delas vai muito além da garantia dos direitos de propriedade. Elas proporcionam a principal estrutura de governança para muitas atividades nas quais as trocas de mercado são socialmente impróprias ou simplesmente ineficazes. Ao mesmo tempo, elas moldam e restringem o comportamento dos agentes econômicos com relação a seus concorrentes, clientes, fornecedores, empregados, agentes governamentais etc. Ao fazer isso, também agem como instrumentos no controle dos "riscos de autodestruição" há muito assinalados por Polányi (1957) e Hirschman (1982).

Note-se, além disso, que mesmo quando encontramos uma governança preponderantemente com "forma de mercado", esta se apresenta entrelaçada com uma densa trama de instituiçôes não-mercantis.

Os produtos farmacêuticos representam um exemplo muito bom a esse respeito. Neste caso, em todos os países dotados de indústrias farmacêuticas eficientes e com fins lucrativos encontramos programas governamentais de apoio à pesquisa biomédica, geralmente em universidades e laboratórios públicos. Ao mesmo tempo, os participantes de tais programas pelo lado das universidades estão também associados à capacitação científica de pessoal que, após o término de sua formação, irá trabalhar nas empresas farmacêuticas. Além disso, praticamente em todos os países, fundos e programas públicos desempenham um papel importante nas compras governamentais de produtos farmacêuticos. E, finalmente, em quase todos os países há diversas formas de regulamentação dos mercados de produtos farmacêuticos que vão muito além das garantias de direitos de propriedade e de honestidade das transaçóes previstas pelos manuais.

Ou então, considere-se o caso dos aviōes e dos serviços de linhas aéreas. Em todos os países possuidores de uma importante produção de aeronaves, os fundos governamentais desempenham um papel significativo na P\&D. E na maioria dos países tanto os aeroportos como os sistemas de controle do tráfego são não apenas financiados mas também operados por agências governamentais. Mesmo nos casos mais simples do transporte rodoviário de cargas e do uso de automóveis, o setor público desempenha um importante papel: construindo e mantendo as estradas, regulamentando a segurança e 
inspecionando os veículos, ao mesmo tempo que grande parte da força policial de qualquer país é constituída de policiais rodoviários...

$\mathrm{Na}$ verdade, mesmo quando forem preenchidas as condições que permitem aos mercados funcionar razoavelmente bem - em termos da distribuição de informações, das normas de interação, etc. - nossa proposta é a de que o papel deles deva ser avaliado não somente em termos de eficiência alocativa (o que quer que isso possa significar no contexto de economias em constante mutação) mas também como ambientes que continuamente possibilitem a experimentação de novos produtos, de novas técnicas de produção e de novas formas de organização. Dentro dessa perspectiva, os mercados, quando funcionam, atuam como mecanismos (imperfeitos) de seleção. Também nesse nível, adquirem máxima importância as formas como a arquitetura institucional organiza as interações entre os agentes e as maneiras como as políticas regulam os comportamentos e as formas da concorrência.

\section{0 caso da geração, adoção e exploração econômica de novos conhecimentos científicos e tecnológicos}

Embora a importância de instituiçôes e de políticas se mostre onipresente em todos os processos de coordenação e de mudança econômica, isto é particularmente verdadeiro no que diz respeito à geração e ao uso de informações e de conhecimentos. Como sabemos, desde os primeiros trabalhos de Nelson (1959) e de Arrow (1962), sob muitos aspectos informações são semelhantes a "bens públicos", no sentido de que seu uso é

- não-exclusivo (o fato de alguém as utilizar não impede que outros também o façam);

- não-excludente (exceto por determinações institucionais como direitos monopolísticos de exploração baseados em patentes).

Além disso, a geração de informações está sujeita a

- custos de produção prévios e antecipados, com um custo praticamente nulo de reprodução; 
- de qualquer modo, há retornos crescentes em seu uso, no sentido de que quanto mais as utilizamos mais fácil isso vai se tornando, e, em termos dinâmicos quanto maior for a probabilidade de aprendermos e de produzirmos nós mesmos outras informações, tanto "melhores", "inéditas" e em algum sentido "inovativas" serão estas.

Deve-se notar que essas mesmas propriedades das informações acarretam intrinsecamente fenômenos de falhas de mercado, para usar o jargão que acabamos de criticar acima (também no sentido de que os preços marginais não servem para orientar uma alocação eficiente de mercado, até com a possibilidade de inexistirem situações de equilíbrio).

É possível obter percepções melhores distinguindo as simples informações dos conhecimentos. Estes incluem ( $i$ ) as categorias cognitivas preexistentes, que permitem que as informações sejam interpretadas e colocadas em uso; (ii) heurísticas de pesquisa e de solução de problemas, irredutíveis a algoritmos bem definidos.

Todas as formas de conhecimentos possuem um aspecto tácito significativo, altamente complementar às informações codificadas, que as torna incorporadas a pessoas ou organizações e um tanto infensas à transmissão. Com efeito, esta é uma das razões fundamentais pelas quais o emparelhamento tecnológico dos países em desenvolvimento continua sendo uma tarefa desafiadora mesmo numa época de globalização e de livre fluxo das informações.

Ocorre que todos os processos de geração de novos conhecimentos científicos e tecnológicos, tanto quanto os de imitação e adaptação tecnológica, envolvem uma ampla variedade de atores complementares, freqüentemente incluindo empresas mercantis mas, junto com elas, instituições públicas de pesquisa e treinamento, "comunidades de intercâmbio", sociedades técnicas e sindicatos, entre outros.

Num sentido fundamental, as instituições e políticas voltadas para o aprendizado tecnológico devem tratar da construção de sistemas nacionais de produção e de inovações.

Com efeito, o processo de emparelhamento envolve inovaçóes de uma maneira essencial. As atividades inovadoras que conduzem o processo obviamente diferem das inovaçóes perseguidas por uma grande parcela das pesquisas 
e do aprendizado tecnológico das economias mais avançadas. As novas tecnologias, e mais geralmente as novas práticas que vão sendo incorporadas, embora sejam novas nos países que procuram emparelhar-se aos mais avançados, estão de modo geral bem estabelecidas nos países situados na fronteira tecnológica. E boa parte das inovações requeridas são de caráter organizacional e institucional. Mas o que ocorre no emparelhamento certamente constitui uma inovação, na medida em que há rupturas em relação a práticas familiares do passado, uma considerável incerteza sobre como fazer funcionar efetivamente as novas práticas, uma necessidade de aprendizado sofisticado pelo uso e pela prática, e um alto risco de malogro, bem como um importante retorno potencial em caso de sucesso.

Ao lado disso, a dinâmica da industrialização baseia-se em grandes transformações estruturais que acarretam uma variação da importância dos diferentes ramos de atividade econômica na geração das inovações tecnológicas e organizacionais. A literatura recente sobre inovações destaca a diversidade das fontes de oportunidades de aprendizado, assim como as complementaridades entre elas (Dosi, 1988a; Cimoli \& Dosi, 1995; Mowery \& Nelson, 1999). De fato, parecem existir, em cada época, tecnologias cujos domínios de aplicação são tão amplos e cujos papéis são tão cruciais que os padrões de mudança técnica de cada país dependem em grande medida das capacidades nacionais de dominar a produção, a imitação e a inovação nessas áreas de conhecimentos cruciais (como no passado, as de engenharia mecânica, da eletricidade e dos dispositivos elétricos, e na atualidade também as tecnologias da informação). Além disso, os vínculos entre as atividades produtivas abrangem com freqüência hierarquias estruturadas, por meio das quais os paradigmas tecnológicos mais dinâmicos desempenham um papel fundamental como fontes de habilidades tecnológicas, oportunidades para solução de problemas e melhorias da produtividade. Assim, essas tecnologias centrais moldam as vantagens e desvantagens absolutas gerais de cada país. Os padrões de mudança técnica de cada país nessas tecnologias não se equiparam às aptidões tecnológicas em outras atividades, mas são complementares a elas. Essas tecnologias centrais com freqüência também implicam a construção de infra-estruturas e de redes básicas comuns a uma ampla gama de atividades (como, por exemplo, a malha elétrica, o sistema rodoviário, as redes de informação e 
telecomunicações). As evidências históricas sustentam fortemente o ponto de vista de que o dinamismo tecnológico auto-sustentado nos países em processo de emparelhamento dificilmente se torna possível sem a progressiva constituição de um setor industrial em expansão e capaz de envolver competências locais num conjunto de tecnologias "centrais".

\section{Complementaridades, incentivos e obstáculos à coordenação}

Tratamos até este momento de algumas das motivações básicas subjacentes às políticas e às instituições que afetam principalmente os mecanismos de acumulação de conhecimentos. Mas o que dizer dos problemas de coordenação, resultantes, em primeira instância, do próprio inter-relacionamento entre múltiplos agentes heterogêneos?

Naturalmente, essa distinção não é tão clara assim: a "coordenação" também envolve os feedbacks (keynesianos) da demanda, e requer graus razoáveis de compatibilidade de incentivos entre os agentes, e também de coordenação nos processos de aprendizado. Contudo, as questões fundamentais sobre a "coordenação" referem-se aqui à tarefa de combinar comportamentos descentralizados, cujos resultados podem ser radicalmente diferentes dependendo das instituiçôes em que estão inseridos, com a importância das políticas em tudo isso.

É interessante observar que esses aspectos básicos parecem ter estado bem claros para algumas figuras fundadoras da disciplina de economia do desenvolvimento (tais como Nurske, Gerschenkron, Rosenstein-Rodan, Hirschman e Prebisch).

Considerem-se as seguintes observações de Nurske (1953):

“em nosso contexto atual, parece-me que o ponto principal é reconhecer como um ataque frontal desse tipo - uma onda de investimentos de capital em vários ramos industriais diferentes - pode ser economicamente bem-sucedido ao mesmo tempo que um ramo qualquer pode vir a ser bloqueado ou desencorajado pelas limitaçóes do mercado preexistente. Nos casos em que uma empresa individual qualquer pode parecer pouco propícia e impraticável, uma ampla gama de projetos em ramos diferentes podem ser bem-sucedidos por estarem apoiados uns nos outros, no sentido de que as pessoas engajadas em cada projeto, agora trabalhando com 
maior capital real por cabeça e com mais eficiência em termos de produção por homens-hora, irão proporcionar um mercado ampliado para os produtos das novas empresas de outros ramos. Dessa forma, os problemas de mercado, e o contrapeso que eles impõem aos incentivos individuais para investir, são removidos ou em algum grau aliviados por uma expansão dinâmica do mercado por meio dos investimentos realizados em vários ramos diferentes". (Nurske, 1953:13-14)

E as de Gerschenkron (1962):

“o processo de industrialização só tem início se os movimentos neste sentido passam a ocorrer, como se fosse ao longo de uma ampla frente, partindo simultaneamente ao longo de muitas linhas de atividades econômicas. Isto constitui em parte o resultado da existência de complementaridades e indivisibilidades nos processos econômicos. Não se pode construir ferrovias, a menos que ao mesmo tempo sejam abertas minas de carvão; a construção de metade de uma ferrovia não irá adiantar, se for preciso ligar um centro no interior do país a uma cidade portuária. Os frutos do progresso industrial em certas linhas são recebidos como economias externas por outros ramos da indústria, cujo progresso por sua vez traz benefícios às primeiras. Ao observar a história econômica da Europa no século XIX, é muito forte a impressão de que apenas quando o desenvolvimento industrial conseguiu começar em grande escala, a tensão entre as condições pré-industrialização e os benefícios esperados da industrialização tornaram-se suficientemente fortes para sobrepujar os obstáculos existentes e liberar as forças que tornaram possíveis as políticas industriais”. (Gerschenkron, 1962:10-11)

Visões similares estão por trás da teoria do big push [grande impulso] de Rosenstein-Rodan (1943; ver a respeito uma versão contemporânea em Murphy et al., 1989): de acordo com Hoff e Stiglitz (2001), uma característica crucial sobre a qual repousa a relevância dos modelos de bigpush está em externalidades difundidas, cujos efeitos de interação se dão por meio de variáveis globais do sistema, tais como a demanda agregada, a demanda industrial de insumos, ou os custos da busca. 
Todos estes são domínios nos quais combinações apropriadas de políticas podem ajudar, e ajudam - como mostraram as experiências históricas - a "desprender-se" do passado e a fomentar trajetórias de desenvolvimento originais. Tem sido assim no passado e, como argumentaremos adiante, há poucas razões para crer que venha a ser radicalmente diferente no futuro, a despeito da assim chamada "globalização".

$\mathrm{Na}$ verdade, as instituições podem ser vistas como tecnologias sociais (Nelson \& Sampat, 2001) controlando externalidades e conformando ou não padrões de atividades inovativas, estruturas de incentivos subjacentes, investimento, propensão a poupar, treinamento de mão-de-obra e competências socialmente distribuídas. Por sua vez, as instituiçôes que governam tais externalidades e complementaridades fazem-no também administrando as regras de interação entre os agentes, moldando as crenças destes e as informações a que podem ter acesso, seu ethos e suas normas de comportamento. (Para uma discussão mais detalhada, ver Hoff \& Stiglitz, 2001.)

\section{0 desenvolvimento institucional de capacitações tecnológicas, organizações e estruturas de incentivo: uma dinâmica co-evolucionária}

Um elemento fundamental dos países que conseguiram equiparar-se com sucesso aos países líderes durante os séculos XIX e XX residiu no ativo apoio governamental ao processo de emparelhamento, envolvendo várias formas de proteção e subsídios diretos ou indiretos. $\mathrm{O}$ argumento condutor dessas políticas foi a necessidade sentida pela indústria local, nos ramos então considerados críticos para o processo de desenvolvimento, de alguma proteção face às empresas mais avançadas dos países líderes. Os argumentos de Alexander Hamilton (1791) a favor da proteção da indústria nascente nos recém-criados Estados Unidos foram praticamente idênticos àqueles produzidos décadas mais tarde por Friederich List (1841) a respeito das necessidades da Alemanha. O famoso ensaio de Gershenkron (1962) documenta as políticas e as novas instituições utilizadas no Continente Europeu para possibilitar o emparelhamento dos diversos países com a Grã-Bretanha. O mesmo relato também se ajusta bem ao caso do Japão, e um pouco mais tarde aos da Coréia e Taiwan. Em muitos países essas políticas engendraram não um emparelhamento bem-sucedido, 
mas um setor local protegido e ineficiente. Contudo, elas também foram a marca registrada, durante o século XX, em todos os países que conseguiram atingir suas metas de emparelhamento. ${ }^{2}$ Precisamos aprender mais sobre as circunstâncias em que a proteção à indústria jovem leva a uma indústria nativa forte, e as condições sob as quais ela é autodestrutiva, e de fato várias das contribuições a este projeto lançam nova luz sobre o assunto.

Essas políticas obviamente irritaram as empresas dos países líderes, e também seus governos, particularmente se a indústria assim apoiada não se limitava a suprir seus mercados internos mas começava a invadir o mercado mundial. Embora os argumentos formulados após a Segunda Guerra Mundial a favor do livre comércio estivessem voltados em sua maioria para a eliminação da proteção e dos subsídios entre os países ricos, e houvesse naquela época certa simpatia pela tese de que alguma proteção a novas indústrias seria freqüentemente útil para os países em desenvolvimento, os tratados internacionais mais recentes têm sido cada vez mais dirigidos contra a proteção face às importações e contra os subsídios de países que procuram emparelhar-se aos mais avançados, partindo de uma posição muito atrasada.

Nós acreditamos que Hamilton e List estavam e continuam certos no sentido de que o emparelhamento bem-sucedido, em ramos nos quais há um comércio internacional considerável, requer algum tipo de proteção a indústrias nascentes ou então outras modalidades de apoio.

Além disso, durante o século XIX e no início do século XX, muitos países em desenvolvimento adotavam regimes legais de propriedade intelectual que não restringiam seriamente a capacidade de suas empresas efetivamente copiarem tecnologias utilizadas nos países mais avançados. São muitos os exemplos em que acordos de licenciamento estiveram envolvidos, mas acreditamos que na maioria das vezes estes foram instrumentos por meio dos quais a transferência de tecnologia foi efetivada em troca de uma taxa ou por força de outras considerações, mais do que instâncias de proteção agressiva da propriedade intelectual por parte das empresas dos países mais avançados.

Tal como nos subsídios e na proteção a indústrias nascentes, os conflitos começaram a surgir em grande parte quando empresas em processo de emparelhamento passaram a avançar no mercado mundial, ou até a exportar para

2 Para uma ampla revisão histórica do papel das políticas em alguns países agora desenvolvidos, ver Reinert (2004). 
os mercados internos das empresas detentoras dos direitos de patente. A crescente freqüência dessas situações foi claramente um importante fator que levou ao tratado dos Trade Related Intellectual Property Rights (TRIPS, Tratado sobre Direitos de Propriedade Intelectual Relacionados ao Comércio). Contudo, esse tratado tornou vulneráveis a processos judiciais não somente as empresas de países em desenvolvimento que estiverem exportando, mas até as que se mantêm trabalhando em seus mercados internos.

Em vista disso, quais são os diferentes domínios de intervenção das políticas, e como eles se projetam em diferentes medidas de políticas e nas instituições relacionadas? A Tabela 1 resume uma taxonomia exploratória.

Em última análise, as políticas e outras atividades de "engenharia institucional" afetam conjuntamente ( $i$ ) as capacidades tecnológicas de organizaçôes individuais e corporativas, e o ritmo em que elas conseguem aprender; (ii) os sinais econômicos percebidos por elas (incluindo, naturalmente, os sinais de lucratividade e os custos de oportunidade percebidos); (iii) as formas como elas interagem umas com as outras e com outras instituiçôes não-mercantis (como agências públicas, bancos de desenvolvimento, entidades de treinamento e pesquisa, etc.).

Ocorre que todos os principais países desenvolvidos possuem atualmente graus de intervenção relativamente altos - sejam eles conscientemente concebidos como políticas industriais ou não - os quais afetam todas as variáveis acima indicadas. E isto se aplica, ainda mais, ao período em que os países desenvolvidos de hoje estavam procurando emparelhar-se ao líder internacional da época. $\mathrm{O}$ que primordialmente diferencia os vários países são os instrumentos, os arranjos institucionais e a filosofia da intervenção.

Em outro trabalho, um de nós estudou o caso das políticas japonesas após a Segunda Guerra Mundial, especialmente com referência às tecnologias eletrônicas, vendo nelas um exemplo paradigmático de políticas de emparelhamento (Dosi, 1984).

É interessante observar que o Japão parece ter agido de forma abrangente com relação a todas as variáveis categorizadas em nossa taxonomia acima. Uma pesada intervenção discricionária na estrutura dos sinais (envolvendo também a proteção formal e informal contra importaçôes e investimentos estrangeiros) recriou o "ambiente de vácuo" geralmente apenas desfrutado 
TABELA 1

Algumas classificações das variáveis e dos processos em que atuam instituições e políticas (gerais e relativas ao aprendizado tecnológico)

\section{Áreas de intervenção de políticas \\ ( I) Oportunidades de inovação científica e tecnológica}

(II) Aprendizado e aptidões tecnológicas socialmente distribuídos

(III) Medidas de Apoio Direcionadas à Indústria, afetando por exemplo os tipos de firmas, etc. - primordialmente a estrutura, a propriedade e as formas de governança das firmas mercantis (locais versus estrangeiras, empresas de propriedade familiar versus companhias de capital aberto, etc.)

(IV) As capacidades dos agentes econômicos (em primeiro lugar as de firmas mercantis) em termos de conhecimentos tecnológicos incorporados a eles, a eficiência e velocidade com que buscam o acesso a novos avanços tecnológicos e organizacionais, etc.

(v) Os sinais e os incentivos econômicos percebidos pelos agentes com fins lucrativos (incluindo preços e taxas de lucratividade reais e esperados, condições para a apropriabilidade de inovações, barreiras ao ingresso, etc.).

(VI) Mecanismos de seleção (superpostas às acima mencionadas)

(VII) Padrões de distribuição de informações e de interação entre os diferentes tipos de agentes (como clientes, fornecedores, bancos, acionistas, administradores, trabalhadores, etc.)

\section{Medidas de políticas}

Políticas científicas, cursos de pósgraduação, projetos tecnológicos "de fronteira"

Políticas educacionais e de treinamento em sentido amplo

Da formação de empresas de propriedade do Estado à privatização das mesmas, das políticas para "campeões nacionais" a políticas que afetam os investimentos de empresas multinacionais, passando por toda a legislação relativa à governança empresarial

Cf. especialmente os pontos (ii), (iii) e também as políticas de P\&D e políticas que afetam a adoção de novos equipamentos, etc.

Regulações de preços, tarifas e quotas no comércio internacional, regimes de Direitos de Propriedade Intelectual, etc.

\section{Instituições relacionadas}

Universidades de pesquisa, centros públicos de pesquisa, instituições médicas, agências espaciais e militares, etc.

Da educação primária às escolas politécnicas, aos land-grant colleges dos EUA

Holdings de propriedade estatal bancos mercantis públicos, "capitalistas de risco" do setor público, empresas de utilidade pública

Agências reguladoras vinculadas agências que controlam os subsídios à pesquisa e à produção, entidades controladoras do comércio, agências que concedem e controlam os Direitos de Propriedade Intelectual.

Autoridades antitruste, instituições que controlam os processos de falência, etc.
Políticas e legislação antitruste e que regulam a concorrência, o ingresso no mercado e as falências; alocação de financiamentos; mercados para propriedade empresarial, etc.

Governança dos mercados de trabalho dos mercados de produtos, relações entre os bancos e o setor produtivo, etc. passando por todos os arranjos coletivamente compartilhados para o controle e a mobilidade do compartilhamento de informações no interior das firmas, formas de cooperação e concorrência entre firmas rivais, etc. (como, por exemplo, as históricas diferenças entre firmas japonesas e anglo-saxônicas)

Fonte: elaboração própria. 
pelo(s) líder(es) tecnológico(s) do momento. Contudo, isso foi contrabalançado por uma feroz rivalidade oligopolística entre as próprias empresas japonesas e uma firme orientação exportadora fomentando o dinamismo tecnológico e prevenindo qualquer exploração da proteção para a mera fixação de preços monopolísticos "secretamente combinados".

É tentador comparar essa experiência japonesa - a despeito de recentes dificuldades, sobretudo macroeconômicas - com outras, na média menos bemsucedidas, tais como as européias, que se basearam fortemente num único instrumento, as transferências financeiras (especialmente subsídios para a P\&D e transferências para formação de capitais), deixando a cargo do funcionamento endógeno do mercado internacional tanto a determinação dos padrões de sinais como as capacidades de resposta das firmas individuais. Existem certamente no exemplo japonês características específicas àquele país, e dificilmente transferíveis para outros. Esse caso, porém, com seu notável resultado, aponta para uma possibilidade geral de se atribuir uma nova forma aos padrões das "vantagens comparativas" à medida que estes vão emergindo da evolução endógena dos mercados internacionais.

As comparações entre as experiências dos países do Extremo Oriente e os da América Latina são igualmente esclarecedoras (cf. Amsden, 1989, 2001; Wade, 1990; Kim \& Nelson, 2000; Dosi et al., 1994, entre outros).

Em resumo, tanto a Coréia como outras economias do Extremo Oriente foram capazes de "contornar" os preços absolutos e relativos e de canalizar os recursos emanados de vantagens comparativas "estáticas" para o desenvolvimento de atividades caracterizadas por oportunidades de aprendizado e elasticidades de demanda mais elevadas (Amsden, 1989). ${ }^{3}$ E elas fizeram isso por meio da penalização do comportamento rentista por parte das firmas privadas.

$\mathrm{Na}$ verdade, os principais atores no aprendizado tecnológico têm sido os grandes grupos econômicos - os chaebols - os quais foram capazes, num estágio muito inicial do desenvolvimento, de internalizar competências para a seleção das tecnologias adquiridas no exterior, para seu uso eficiente e sua adaptação e, não muito depois, foram também capazes de desenvolver impressionantes aptidões de engenharia (cf. Kim, 1993).

Esse processo foi apoiado mais adiante por um conjunto de instituições

3 Sobre a importância "perversa" da busca de lucro no processo de desenvolvimento, ver Khan (2000a, 2000b). 
e redes para o aperfeiçoamento de recursos humanos (Amsden, 1989). Tudo isso contrasta nitidamente com a experiência latino-americana, na qual os arranjos entre o Estado e o setor privado têm sido freqüentemente mais indulgentes com a ineficiência e o comportamento rentista, e menos atentos à acumulação de capacidades e de competências tecnológicas socialmente difundidas.

Em última análise, o sucesso ou o malogro parecem depender das combinações de diferentes arranjos e políticas institucionais, na medida que estes, por um lado, afetam os processos de aprendizado dos indivíduos e das organizações, e influenciam os processos de seleção (inclusive, naturalmente, a concorrência no mercado), pelo outro.

A experiência histórica certamente mostra uma grande variedade de combinaçôes, específicas para cada país e setor, entre os tipos de políticas acima apresentados. Há no entanto algumas sutis regularidades.

Primeiro, uma regularidade, válida para a Europa e os EUA desde o século XIX até os tempos atuais, tem sido a centralidade das agências públicas, tais como as universidades, e das políticas públicas na geração e estabelecimento de novos paradigmas tecnológicos.

Em segundo lugar, e de maneira correlata, "os incentivos freqüentemente não são suficientes”. Um papel crucial das políticas é o de afetar as capacidades dos atores, especialmente no caso já citado de novos paradigmas tecnológicos, mas também em todos os casos de emparelhamento nos quais nenhuma estrutura de incentivos razoável conseguiria ser suficiente para motivar atores privados a superar grandes defasagens tecnológicas.

Terceiro, a disciplina do mercado é útil na medida em que ela extirpa, no interior de populações particulares de firmas, aquelas que apresentam baixo desempenho, e recompensa as que têm alto desempenho. Contudo, nada garante que choques seletivos excessivamente fortes não venham a eliminar as próprias populações como um todo, eliminando assim também qualquer possibilidade futura de aprendizado.

Quarto, certas políticas - especialmente as voltadas para o emparelhamento - geralmente enfrentam a necessidade de balancear medidas dirigidas à construção de capacidades (e também à proteção do "novo aprendizado") com mecanismos que limitem a inércia e o comportamento rentista. Esta última característica, por exemplo, constitui na verdade um dos principais 
elementos ausentes da tradicional experiência latino-americana de substituição de importaçôes, enquanto que a primeira tem faltado em muitas das políticas de "liberalização" mais recentes.

Quinto, em termos históricos, um esforço bem-sucedido de emparelhamento em termos de renda per capita e de salários sempre tem sido acompanhado pela incorporação dos novos e mais dinâmicos paradigmas tecnológicos, independentemente dos padrões iniciais de vantagens comparativas, de especialização e dos sinais emitidos pelo mercado. Nossa conjectura é a de que, ceteris paribus, a necessidade estrutural de políticas que também afetem os padrões dos sinais econômicos (incluindo os preços relativos e as lucratividades relativas) à medida em que eles emergem do mercado internacional será tanto maior quanto maior for a distância que separa o país da fronteira tecnológica. Foi isso que Amsden (1989) provocativamente chamou de políticas de "deixar os preços errados" deliberadamente. Inversamente, os mecanismos endógenos do mercado tendem a comportar-se de maneira "virtuosa" naqueles países que se encontram na fronteira, especialmente das tecnologias mais novas/mais promissoras. Isso tem sido amplamente confirmado pela experiência histórica: com freqüência o comércio incondicionalmente livre tem sido advogado e plenamente explorado apenas pelos países detentores da liderança política e tecnológica.

\section{Sobre algumas escolhas fundamentais confrontadas pelas políticas e instituições nas economias em fase de aprendizado}

Num mundo caracterizado pela mudança técnica (tanto a "contínua", ao longo de trajetórias tecnológicas bem definidas, como a "descontínua", vinculada à emergência de novos paradigmas tecnológicos), as defasagens e as lideranças tecnológicas moldam os padrões dos sinais de lucratividade intersetoriais e interprodutos e, dessa forma, também os padrões da alocação microeconômica de recursos. Estes últimos, contudo, podem afetar o dinamismo econômico de longo prazo da economia de cada país, em termos tanto das taxas de crescimento da renda consistentes com as restriçóes do balanço de pagamentos como da inovatividade tecnológica. Em última análise, isto se dá porque os efeitos de uma multiplicidade de sinais (relacionados à lucratividade, 
ao crescimento de longo prazo da demanda e às oportunidades tecnológicas) nos processos microeconômicos de ajuste têm uma grande probabilidade de serem assimétricos.

Em outro trabalho, um de nós aprofundou esse ponto estabelecendo uma distinção entre as noções de (i) eficiência alocativa; (ii) eficiência inovativa (ou "schumpeteriana"); e (iii) eficiência de crescimento de padróes particulares de produção (Dosi et al., 1990). Naquele trabalho agora concordamos que, especialmente em países distantes da fronteira tecnológica, padrões de alocação de recursos que são "eficientes" em função da distribuição imposta de capacidades tecnológicas e de preços relativos podem facilmente acarretar efeitos negativos de longo prazo em termos das elasticidades de demanda dos bens que um país conseguirá produzir (a "eficiência de crescimento") e do potencial inovativo associado a isso (o critério de "eficiência inovativa"). Sempre que surgem escolhas entre diferentes noçôes de eficiência, resultados macroeconômicos "subótimos" ou "perversos" podem emergir. Dado que o padrão futuro de vantagens/desvantagens tecnológicas também está relacionado aos padrôes alocativos do presente, podemos ver funcionando aqui os processos dinâmicos que Kaldor chamou de "causação circular", com os sinais econômicos relacionados às rentabilidades intersetoriais - que levam diretamente a "vantagens comparativas" e especializaçôes relativas certamente controlando e monitorando a eficiência alocativa dos vários empregos produtivos, mas podendo também desempenhar um papel mais ambíguo ou até mesmo perverso com relação às tendências macroeconômicas de longo prazo.

Note-se que essas possíveis escolhas têm pouco a ver com a eficiência informacional dos processos de mercado (ainda que, naturalmente, formas variadas de assimetria informacional provavelmente tornem as coisas piores). Ao contrário, a condição geral de um sistema econômico é de que as oportunidades tecnológicas variem entre produtos e entre setores. Além disso, no interior de cada tecnologia e de cada setor, as capacidades tecnológicas de cada firma e de cada país estão associadas ao processo real de produção e de inovação vigentes na área. Assim, os mecanismos relativos à alocação de recursos afetam hoje também aqueles cujas competências técnicas serão acumuladas, e nos quais (possivelmente) se empreenderão inovações e se 
colherão benefícios gerados por economias de escala, etc. Mas o potencial de tais efeitos difere largamente entre tecnologias e setores. Este é um outro aspecto da irreversibilidade dos processos econômicos: as escolhas alocativas presentes influenciam a direção e a velocidade da evolução futura dos coeficientes tecnológicos. Sempre que abandonamos a idéia de tecnologia como um conjunto de projetos e concebemos o progresso técnico como algo gerado em conjunto com a produção, torna-se possível imaginar um sistema econômico que é dinamicamente melhor do que em outras situações (em termos de produtividade, inovatividade, etc.), se ele evolui em desequilíbrio vis-à-vis as condições de eficiência alocativa.

É relativamente fácil ver como podem surgir tais escolhas entre "eficiência alocativa" e "eficiência inovativa". Os padrões de especialização (com suas propriedades de eficiência alocativa) são determinados, para cada país, pelo tamanho relativo das defasagens ou dos avanços tecnológicos específicos ao setor (mais detalhes em Dosi et al., 1990b). Sempre que a defasagem for maior em todas as tecnologias mais dinâmicas (i.e. nas caracterizadas pelas maiores oportunidades tecnológicas), a eficiência alocativa estará em conflito direto com a eficiência inovativa. Tendemos a sugerir que a probabilidade da ocorrência de tais escolhas entre as duas noções de eficiência é proporcional à distância que separa cada país da fronteira nas tecnologias mais novas, mais dinâmicas e mais penetrantes. ${ }^{4}$

Um argumento similar se aplica às escolhas entre a eficiência alocativa e a de crescimento: em última análise os diversos países podem muito bem acabar especializando-se "eficientemente" na produção de bens que um número relativamente pequeno ou até decrescente de consumidores no mundo todo desejam comprar, restringindo assim suas possibilidades de crescer consistentemente devido a limitações impostas pelo balanço de pagamentos. ${ }^{5}$

Em condições de rendimentos não-decrescentes (e freqüentemente crescentes), não há uma maneira direta para que os mercados possam relacionar

4 Conclusões algo similares sobre a importância crucial da distância até a fronteira tecnológica internacional em termos da combinação de medidas de políticas podem ser extraídas dos modelos "neo-schumpeterianos" de crescimento: cf. Aghion \& Howitt (2005).

5 Tanto em Dosi et al., (1990) como em Cimoli (1988) argumenta-se a favor dessa proposição com base num modelo contendo uma dinâmica de crescimento Kaldor-Thirlwall aplicada a diversas defasagens tecnológicas no nível das mercadorias. Uma proposição semelhante também se mostrou válida partindo de suposições mais convencionais: cf. Rodrick (2005). 
as variáveis eficiências inovativa e de crescimento das diversas mercadorias aos sinais de lucratividade relativa para os agentes microeconômicos. ${ }^{6}$

Isso define também um domínio fundamental para as políticas.

Uma compreensão detalhada dos, e uma intervenção nos padrões de sinais, regras de respostas alocativas e formas de organização institucional da "máquina econômica" são particularmente importantes naquelas fases de transição de um regime tecnológico (baseado em paradigmas tecnológicos antigos) para um regime novo. Esses períodos históricos definem um novo conjunto de oportunidades e ameaças para cada país: os padrões internacionais de geração e difusão de tecnologias tornam-se mais fluidos assim como também, em conseqüência, os fluxos comerciais internacionais e os níveis relativos de renda per capita.

A economia contemporânea - segundo cremos - está passando por uma mudança desse tipo. Nesse processo, vantagens comparativas se transformam em profecias autocumpridas de um conjunto bem-sucedido de ações institucionais e estratégias privadas: expost, o sucesso econômico e tecnológico torna "ótimo" do ponto de vista do economista aquilo que ex ante constituía um sonho político.

\section{Algumas intricadas questões operacionais}

Tendo reconhecido isso, lições interessantes provavelmente virão da comparação detalhada dos resultados de diferentes combinaçôes de arranjos institucionais e medidas de políticas conforme têm sido observados historicamente.

Por exemplo:

- Que lições podem ser extraídas da comparação entre as filosofias de "substituição de importaçôes" e as de "promoção das exportaçôes"?

- Como é que a acumulação de capital complementa o aprendizado tecnológico?

6 Traduzindo o mesmo argumento numa linguagem mais familiar para o economista, a disseminada possibilidade de compensações entre as eficiências alocativa, schumpeteriana e de crescimento nasce do fato de que o caso geral é um caso de não-convexidade dos conjuntos de possibilidades de consumo e produção e de retornos dinamicamente crescentes e de dependências de trajetória dos avanços tecnológicos. Sobre esse ponto, dentro de uma literatura que está crescendo, veja-se os argumentos complementares de Atkinson \& Stiglitz (1969), David (1988), Arthur (1994), Dosi et al. (1990), Krugman (1996), Antonelli (1995), Cimoli (1988), Castaldi \& Dosi (2006). 
- Qual tem sido exatamente a importância do setor financeiro e qual a sua relação com as atividades produtivas?

- Como se comparam as estratégias de aquisição tecnológica baseadas em investimentos de empresas multinacionais com as estratégias baseadas no crescimento das firmas locais?

- Quais são os dispositivos de políticas mais eficientes para refrear os comportamentos rentistas que freqüentemente emergem como subproduto dos esforços para fomentar o aprendizado por parte das firmas locais?

- Qual é o papel das instituições públicas de pesquisa no processo de emparelhamento?

- Como é afetado este último pelos diferentes regimes dos Direitos de Propriedade Intelectual?

- Como é que as políticas macroeconômicas influenciam os comportamentos microeconômicos e os processos de ajustamento, especialmente no que diz respeito ao aprendizado tecnológico e organizacional?

$\mathrm{Na}$ verdade várias dessas questóes - cruciais para o entendimento da efetividade de diferentes combinações de políticas - têm sido tratadas por várias contribuiçóes da presente força-tarefa.

Contudo, a questão mais intricada de todas possivelmente diga respeito ao grau em que as lições do passado podem ser úteis sob o atual regime de relações econômicas internacionais.

\section{Políticas em um "mundo globalizado": os novos desafios}

O raciocínio apresentado até agora, segundo acreditamos, aplica-se em geral à generalidade dos processos de emparelhamento e industrialização, a despeito da óbvia diversidade histórica dos mesmos. Mas quais são as liçôes específicas que podem ser derivadas da fase mais recente do desenvolvimento internacional?

Na verdade, o último par de décadas da "globalização" tem avançado lado a lado com poderosos esforços para impor um regime de políticas baseadas em formas um tanto extremadas de ortodoxia econômica, algo que, no caso dos países em desenvolvimento, recebeu o nome de "Consenso de Washington", do qual a América Latina tem sido uma vítima exemplar.

A liberalização do comércio internacional, eventualmente conduzindo 
ao livre comércio, foi uma peça-chave do tal "consenso" - algumas vezes, na verdade, imposto pelas armas. Essa ênfase na liberalização do comércio era considerada natural: dizia-se que os países da América Latina haviam estagnado por trás de barreiras protecionistas. A substituição de importações, segundo o mesmo ponto de vista, provara ser uma estratégia de desenvolvimento altamente ineficaz. Em muitos países, as indústrias estavam fabricando produtos com valor adicionado negativo, e a inovação estava sendo sufocada. $\mathrm{O}$ argumento habitual - de que o protecionismo em si sufocava a inovação era na verdade um pouco confuso. Os governos poderiam ter gerado uma concorrência entre as firmas locais, o que teria proporcionado incentivos à importação de novas tecnologias. Foi essa falha em criar uma concorrência interna, mais que o protecionismo em relação ao exterior, que acabou causando a estagnação. Naturalmente, uma concorrência de procedência externa teria proporcionado um importante desafio para as firmas locais. Mas é possível que nessa competição unilateral as firmas locais iriam preferir abandonar a corrida em vez de ter que enfrentá-la. Os consumidores poderiam ter-se beneficiado disso, mas os seus efeitos sobre o crescimento poderiam ser algo mais ambíguos. A liberalização do comércio internacional pode fomentar a concorrência, mas ela não o faz automaticamente. Se essa liberalização do comércio se dá numa economia com um importador monopolista, as rendas podem ser simplesmente transferidas do governo para o monopolista, com pouca redução dos preços. Portanto, a liberalização do comércio internacional não é necessária nem suficiente para criar uma economia competitiva e inovativa.

Pelo menos tão importante como fomentar a concorrência num setor econômico protegido das importações, é a promoção da competição no lado das exportaçôes. O sucesso das economias do Leste Asiático constitui um exemplo poderoso desse fato. Ao permitir que cada país tire vantagens de sua força competitiva, o comércio internacional contribui para elevar os salários e expandir as oportunidades de consumo. Durante as últimas décadas, no caso dos países do Extremo Oriente, o comércio internacional tem feito exatamente isso.

Além disso, como mostram as comparações entre diferentes experiências na América Latina e no Extremo Oriente, um choque de livre comércio não desencadeia automaticamente qualquer aumento da acumulação de conhecimentos e de capacidades inovativas. Pelo contrário, em um mundo caracterizado por múltiplas formas de rendimentos crescentes localizados ("localizados" 
no que se refere às tecnologias e também em termos espaciais), uma maior integração pode muito bem levar a fenômenos de diferenciação crescente com um auto-reforço e travamento em atividades produtivas específicas, bem como dos padrões de especialização, e das capacidades tecnológicas (ou da falta delas), conforme se mostrou na discussão acima. Dito de outra forma, é fácil mostrar que num mundo que se torna, em algum nível, cada vez mais integrado - mas não (grosso modo) idêntico em termos de condições iniciais, instituições, capacidades tecnológicas, mecanismos de interação econômica poderia estar sujeito a várias formas "locais" de círculos viciosos ou virtuosos, hoje em dia, mais ainda que no passado.

Finalmente, o impacto de uma maior integração provavelmente dependerá dos meios pelos quais ela é implementada. A experiência de muitos países latino-americanos é um bom exemplo disso. Quando os choques macro ("globalizantes") subitamente induziram uma maior seleção entre as firmas locais, uma massiva mortalidade destas freqüentemente levou a uma aparente redução da diferença da produtividade vis-à-vis a fronteira internacional. Mas isto pareceu acontecer - ao menos nos países da América Latina - junto com fortes aumentos tanto nas taxas de desemprego (com a transferência de partes da força de trabalho de situações de baixa produtividade para situações de produtividade zero), como a restriçóes cada vez maiores ao crescimento, impostas pelo balanço externo, em vista das baixas elasticidades das exportações em relação ao crescimento da economia mundial e das altas elasticidades das importações em relação ao crescimento interno (cf. Cimoli \& Correa, 2002).

Certamente tanto as recentes mudanças - políticas e econômicas - nas relações internacionais como a atual revolução das tecnologias da informação e das comunicações estão dando novas formas às oportunidades e às restrições enfrentadas pela formulação de políticas e pela "engenharia institucional", mas de forma alguma reduziram sua importância. Antes pelo contrário: elas requerem novas formas de governança, que agora estamos apenas começando a explorar.

Assim, por exemplo, no lado tecnológico, as características dos conhecimentos produtivos mudaram, nos dias de hoje, em comparação com, digamos, os paradigmas eletromecânicos no âmbito dos quais países como a Alemanha e os EUA alcançaram e ultrapassaram a Inglaterra há quase um 
século, e esses conhecimentos podem também ser em parte diferentes do tipo de conhecimentos - em boa parte centrados nas tecnologias da informação de primeira geração - por meio dos quais, mais recentemente, países como Coréia e Taiwan conseguiram aproximar-se da fronteira tecnológica. Por sua vez, com as mudanças no tipo de conhecimentos que os países precisam acumular e aperfeiçoar, também surgem com freqüência mudanças nos pacotes de políticas mais apropriadas relativas, por exemplo, aos tipos de ensino oferecidos, ao apoio às firmas nacionais face às empresas multinacionais e a novos ingressantes; ao papel dos centros de pesquisa e de treinamento públicos. $\mathrm{Na}$ verdade, muitas das contribuiçōes apresentadas à presente força-tarefa tratam dessas questôes.

Também houve mudanças importantes nos regimes do comércio internacional e da proteção aos direitos de propriedade, associadas à OMC, aos TRIPS e a vários acordos bilaterais. Esses novos regimes têm implicado, em primeiro lugar, uma redução dos graus de liberdade de que podem desfrutar os países em desenvolvimento em suas políticas comerciais, sendo notório que todos os países que se emparelharam nas ondas de industrialização anteriores puderam fazer uso de um grande cardápio de quotas, tarifas e várias formas de barreiras não-tarifárias. Em segundo lugar, eles envolvem uma proteção internacional muito mais agressiva dos vigentes Direitos de Propriedade Intelectual e, assim, permanecendo iguais as outras coisas, também criam maiores dificuldades para imitar ou "reinventar" produtos e processos de produção já existentes -atividades estas que estiveram no âmago das primeiras fases da industrialização, dos EUA da Suíça, do Japão, da Coréia...

Portanto, uma questão fundamental de política diz respeito aos graus de liberdade deixados às intervençôes públicas discricionárias que apóiem, de maneiras diversas, tecnologias, setores e firmas específicas. Quão severas são as novas restrições internacionais? Notemos que a resposta neste caso provavelmente variará de setor para setor e de tecnologia para tecnologia. E é provável que ela dependa também da distância de cada país em relação à fronteira tecnológica. Por exemplo, muitos países africanos e alguns latinoamericanos poderiam não ser diretamente afetados por um endurecimento dos regimes de Direitos de Propriedade Intelectual, a começar por disporem de poucas aptidões para imitar (embora ainda possam ser negativamente afetados por serem obrigados a comprar remédios ou software a preços ridículos 
de multinacionais do primeiro mundo, em vez de fazê-lo junto a países "mais avançados" mas ainda "imitadores"). Ao mesmo tempo, regimes de Direitos de Propriedade Intelectual mais severos podem muito bem representar um grande obstáculo para os países em processo de emparelhamento mais avançados.

Diante disso, quais são as facilidades para contornar as regras existentes? Ou seja, dito de outra forma, qual a urgência de se reformarem os atuais regimes de comércio internacional e dos Direitos de Propriedade Intelectual numa perspectiva "favorável ao desenvolvimento"?

Chegou o momento de construir um "novo consenso" sobre todas essas questôes, um consenso que tenha como característica proeminente a exploração de formas de governança institucional que também fomentem a acumulação de conhecimentos nos países em desenvolvimento e que tornem sua exploração econômica eficiente e consistente com os múltiplos interesses de seus agentes motivados pelo lucro. Sugerimos que um tal "consenso" seja baseado numa visão pragmática dos mercados, por meio da qual estes possam às vezes funcionar num sentido "desenvolvimentista", e outras vezes não. E, mesmo quando eles funcionam, que sua efetividade não seja separada das contribuições de instituições e políticas de fomento. E, last but not least, esse consenso deverá ser sensível a questôes de eqüidade e de acesso à repartição dos benefícios do crescimento decorrentes do aprendizado organizacional e tecnológico.

As contribuições apresentadas a esta força-tarefa, segundo diferentes ângulos, conduzem-nos de fato nessa direção.

ENDEREÇOS PARA CORRESPONDENCIA:

Mario Cimoli-mcimoli@eclac.cl

Av. Dag Hammarskjöld, 3477 - Viactura - Casilla 179-D - Santiago de Chile

Giovanni Dosi-gdosi@sssup.it

Piazza Martiri della Libertà, 33 - 56127 - Pisa, Italia

Richard R.Nelson-rrn@columbia.edu

Columbia University - School of International and Public Affairs - 420 West - 118th Street - New York, NY 10027

Joseph Stiglitz-jes322@columbia.edu

Uris Hall, Room 814 - Columbia University - 3022 Broadway - New York, NY 10027 


\section{Referências bibliográficas}

Aghion, P.; Durlauf, S. (orgs.), Handbook of Economic Growth, Amsterdam: Elsevier, no prelo, 2005.

Aghion, P.; Howitt, P., "Appropriate Growth Policy: A Unifying Framework", in The 2005 Joseph Schumpeter Lecture, Amsterdam: European Economic Association Congress, ago., 2005.

Amsden, A., Asia is Next Giant, Cornell University Press, 1989.

, The Rise of the Rest. Challenges to the West from Late-Industrializing Economies, Oxford: Oxford University Press, 2001.

Antonelli, C., The Economics of Localized Technological Change and Industrial Dynamics, Boston: Kluwer Publishers, 1995.

Arrow, K., "Economic Welfare and the Allocation of Resources for Invention", in Nelson, R.R. (org.), The Rate and Direction of Inventive Activity, Princeton: Princeton University Press, 1962.

Arthur, W.B., Increasing Returns and Path Dependence in the Economy, Ann Arbor: University of Michigan Press, 1994.

Atkinson, A.; Stiglitz, J., "A new view of technological change", Economic Journal v.79, p.573-578, 1969.

Castaldi, C.; Cimoli, M.; Correa, N.; Dosi, G., Technological Learning, Policy Regimes and Growth in a "Globalized" Economy: General Patterns and the Latin American Experience, Pisa: Sant'Anna School of Advanced Studies, LEM Working Paper 2004/01, 2004.

Castaldi, C.; Dosi, G., "The Grip of History and the Scope for Novelty: Some results and Open Questions on Path Dependence in Economic Processes", in Wimmer, A.; Kössler, R. (orgs.), Understanding Change, p.99-128, Palgrave MacMillan, 2006.

Cimoli, M., "Technological gaps and institutional asymmetries in a North-South model with a continuum of goods", Metroeconomica, v.39, p.245-274, 1988.

Cimoli, M.; Dosi, G., "Technological Paradigms, Patterns of Learning and Development. An Introductory Roadmap", Journal of Evolutionary Economics, v.5, p.243-268, 1995. 
Cimoli, M.; Correa, N. (2002), "Trade openness and technological gaps in Latin America: a 'lowgrowth' trap", in Ocampo, J.A., 2005.

David, P.A., Path Dependence: Putting the Past into the Future of Economics, Stanford University, Institute for Mathematical Studies in the Social Science, Technical Report 533, 1988.

Dosi, G., Technical Change and Industrial Transformation. Londres: Macmillan e Nova York: St. Martin Press, 1984.

, "Institutions and Markets in a Dynamic World", The Manchester School of Economic and Social Studies, v.56, p.119-146, 1988.

"Sources, procedures and microeconomic effects of innovation", Journal of Economic Literature, v.26, n.3, p.1.120-1.171, 1988a.

Dosi, G.; Pavitt, K.; Soete, L., The Economics of Technical Change and International Trade, Londres: Harvester Wheatsheaf, 1990.

Dosi, G.; Freeman, C.; Fabiani, S., "The Process of Economic Development. Introducing some stylized Facts and Theories on Technologies, Firms and Institutions", Industrial and Corporate Change, v.3, p.1-45, 1994.

Freeman, C., The Economics of Industrial Innovation. Londres: Francis Pinter, $2^{\underline{a}} \mathrm{ed}$., 1982.

"Technological infrastructures and international competitiveness", Industrial and Corporate Change, p.541-569, 2004.

Gerschenkron, A., Economic Backwardness in Historical Perspective. Cambridge, Harvard University Press, 1962.

Greenwald, B.; Stiglitz, J., "Externalities in Economics with Imperfect Information and Incomplete Markets", Quarterly Journal of Economics, v.101, p.229-264, 1986.

Hamilton, A., (1791), "Report on the Subject of Manufactures", in Syrett, H.C. et al., The Papers of Alexander Hamilton, vol.X, Nova York: Columbia University Press, 1966.

Hausmann, R.; Hwang, J.; Rodrick, D., What You Export Matters, CID Working Paper No. 123, Center for International Development at Harvard University, Cambridge, MA, 2005.

Hirschman, A.O., The Strategy of Economic Development, New Haven: Yale University Press, 1958. 
Hirschman, A.O., "Rival Interpretations of Market Society: Civilizing, Destructive, or Feeble?”, Journal of Economic Literature, v.20, p.1.463-1.484, 1982.

Hoff, K., "Market Failures and the Distribution of Wealth: A Perspective from the Economics of Information", Politics and Society, v.24, p.411-432, 1996.

Hoff, K.; Stiglitz, J., "Modern Economic Theory and Development", in Meier e Stiglitz (2001).

Lall, S., Selective Industrial and Trade Policies in Developing Countries: Theoretical and Empirical Issues, QEH Working Paper Series, 48, 2000.

Landes, D., The Unbound Prometheus, Cambridge: Cambridge University Press, 1969.

List, F., (1841), The National System of Political Economy, trad. Lloyd, S.S., Londres: Longmans, Green and Co.; a primeira tradução inglesa é de 1885.

Khan, M.H., "Rents, Efficiency and Growth", in M.H. Khan e J.K. Sundaram (orgs.), Rents, Rent-Seeking and Economic Development: Theory and Evidence in Asia, Cambridge University Press, 2000.

Khan, M.H. (2000), "Rent-seeking as Process", in Khan (2000).

Kim, L.,"National System of Industrial Innovation: Dynamics of Capability Building in Korea", in Nelson, R.R. (org.), National Innovation Systems: A Comparative Analysis, Nova York: Oxford University Press, 1993.

Kim, L.; Nelson, R.R., Technology, Learning, and Innovation: Experiences of Newly Industrializing Economies, Cambridge University Press, 2000.

Krugman, P.R., The Self-Organizing Economy, Cambridge, MA, e Oxford: Blackwell Publishers, 1996.

Mazzoleni, R.; Nelson, R.R., "The Role of Research at Universities and Public Labs in Economic Catch-up", Nova York, Columbia University, Initiative for Policy Dialogue, Working Paper, 2005.

Meier, G.M.;. Stiglitz, J. (orgs.), Frontiers of Development Economics. Oxford, Nova York: Oxford University Press, 2001.

Mowery, D.C.; Nelson, R.R., Sources of Industrial Leadership: Studies of Seven Industries, Cambridge: Cambridge University Press, 1999.

Murphy, K.M.; Shleifer, A.; Vishny, R.W., "Industrialization and the Big Push", Journal of Political Economy, v.97, p.1.003-1.026, 1989. 
Nelson, R.R., "The Simple Economics of Basic Scientific Research", Journal of Political Economy, v.67, p.297-306, 1959.

Nelson, R.R. (org.), Government and Technical Progress, Nova York: Pergamon Press, 1982.

, "The co-evolution of technology, industrial structure and supporting institutions", Industrial and Corporate Change, v.3, p.47-64, 1994.

Nelson, R.R.; Sampat, B., "Making sense of institutions as a factor shaping economic performance", Journal of Economic Behavior \& Organization, v.44, p.31-54, 2001.

Nelson, R.R., "Economic Development from the Perspective of the Evolutionary Theory", Mimeo, Columbia University, Nova York, 2004.

(org.), The Limits of Market Organization, Nova York: Russell Sage Foundation, 2005.

Nurske, R., Problems of Capital Formation in Underdeveloped Countries, Nova York: Oxford University Press, 1953.

Ocampo, J.A. (org.), Beyond Reforms, Structural Dynamics and Macroeconomic Vulnerability, Stanford: Stanford University Press, 2005.

, "The Quest for Dynamic Efficiency: Structural Dynamics and Economic growth in Developing Countries", in Ocampo, 2005.

Perez, W.; Di Maio, M., "Industrial polices in Latin America in the last fifteen years: the political economy of consensus building around specific policy schemes", Nova York, Columbia University, Initiative for Policy Dialogue, Working Paper, no prelo.

Polányi, K., The Great Transformation. Boston: Beacon Press, 1957.

Reinert, E.S., "How Rich Nations got Rich", Essays in the History of Economic Policy. Working paper Nr. 1, 2004, SUM - Centre for Development and the Environment, University of Oslo.

Rodrik, D., "Trade and Industrial Policy Reform", in Behrman, J.; Srinivasan, T.N. (eds.), Handbook of Development Economics, Vol. III, p.2.925-2.982. Amsterdam: North Holland, 1995.

, (org.), in Search of Prosperity: Analytic Narratives on Economic Growth, Princeton: Princeton University Press, 2003. 
, "Growth Strategies", in Aghion, P.; Durlauf, S. (2005).

Rosenberg, N., Perspective on Technology, Cambridge: Cambridge University Press, 1976.

Inside the Blackbox, Cambridge: Cambridge University Press, 1982.

Rosenstein-Rodan, P., "Problems of Industrialization of Eastern and Southeastern Europe", Economic Journal, v.53, p.210-211, 1943.

Stiglitz, J., Whither Socialism?, Cambridge, Mass.: The MIT Press, 1994.

, "Some Lesson from the East Asian Miracle", World Bank Research Observer, v.11, p.151-177, 1996.

, "More Instruments and Broader Goals Moving toward the Post-Washington Consensus", in Chang, H. (org.), The Rebel Within, p.17-56, Londres: Wimbledon Publishing Company, 2001. - Originally presented as the 1998 WIDER Annual Lecture, Helsinki, jan., 1998.

Veblen, T., Imperial Germany and Industrial Revolution, Londres: Macmillan, 1915.

Wade, R., Governing the Market: Economic Theory and the Role of Government in East Asian Industrialization, Princeton University Press, 1990. 